\title{
Hidrofobik Bakır Stearat Sentezinin Box-Benhken Tasarımıyla Modellenmesi
}

\author{
Seyfullah Keyf ${ }^{*}$ \\ ${ }^{1}$ Yıldız Teknik Üniversitesi, Kimya Metalurji Fakültesi, Kimya Müh. Bölümü, İstanbul, Türkiye (ORCID: 0000-0001-8846-0674)
}

(İlk Geliş Tarihi 10 Nisan 2019 ve Kabul Tarihi 5 Ağustos 2019)

(DOI: 10.31590 /ejosat.551852)

REFERENCE: Keyf, S., (2019). Hidrofobik Bakır Stearat Sentezinin Box-Benhken Tasarımıla Modellenmesi. Avrupa Bilim ve Teknoloji Dergisi, (16), 834-840.

Öz

Süperhidrofobik yüzeyler nanoteknolojinin bir uygulaması olup, yoğun araştırmalar yapılmaktadır. Su damlası temas açısı $150^{\circ}$ 'den büyük temas açısına sahip ise "süperhidrofobik" , 90-150 arası olanlar hidrofobik olarak tanımlanır. Bir yüzeyin süperhidrofobik özellik gösterebilmesi için üzerinde mikrometre mertebesinde pürüzlülüğe sahip malzemeden hazırlanmış olması gerekir. Hidrofobik kaplama, günümüz şartlarında sıklıkla ihtiyaç duyulur hale gelmiştir. Bu amaçla mikron ölçekte bakır stearat sentezlenmiştir. Reaksiyon sıcaklığı, karıştırma hızı ve karıştırma zamanı değişken parametreleri Box-Behnken tasarımı kullanılarak temas açısı ölçümleri için cevap fonksiyonu oluşturulmuştur. Cam yüzeyi üzerinde suyun temas açısının açısı $35^{\circ}+-2$ derece olduğu ölçüldü. Bakır stearat sentez için yapılan deneylerde sırasıyla sıcaklık, reaksiyon zamanı ve karıştırma hızı incelendi. 20, 40, $60{ }^{\circ} \mathrm{C}$ sıcaklık, 2, 6,10 dak. reaksiyon zamanı ve 200,400,600 rpm karıştırma hızı değişkenlerine göre yapılan deneylerde cam yüzey üzerine yapılan kaplamaların temas acıları 126-138.5 arasında değişmektedir. Üç faktörlü Box-Behnken tasarım yöntemi kullanılmıştır. Elde edilen cevap yüzeyi ile bağımsız değişken arasında elde edilen grafikler ve cevap yüzeyi denklemi incelendiğinde; en önemli parametrenin sıcaklık olduğu, ikinci önemli parametrenin karıştırma hızı olduğu, reaksiyon zamanı parametresinin ise temas açısındaki etkisinin çok az olduğu belirlendi. Reaksiyon zamanı yerine öncelikle $\mathrm{pH}$, katı sıvı derişimi faktör olarak incelenmesinin yararlı olacağ belirlendi.

Anahtar Terimler: Bakır Stearat, Box-Behnken Tasarımı, Hidrofobik

\section{Responce Surface with Box-Benhken Design for Hydrophobic Copper Stearate Synthesis}

\begin{abstract}
Superhydrophobic surface is one of the applications of nanotechnology and intensive researches have been done in this subject. Surfaces that have water contact angles larger than $150^{\circ}$ are called "superhydrophobic" and between $90-150^{\circ}$ are called "hydropobic". To exhibit superhydrophobic feature, a surface should have both micron scale roughness and inherently should have been prepared by a hydrophobic material. Hydrophobic coating frequently used in different sectors at the present time. For this purpose it was synthesized nanoscale copper stearate. Reaction temperature, stirring speed and stirring time response function for variable parameters Box-Behnken design using contact angle measurements were formed. The water contact angle on the glass surface was measured to be $35^{\circ} \pm 2$ degrees In the experiments for copper stearate synthesis, temperature, reaction time and stirring speed were examined respectively. $20,40,60$ ${ }^{\circ} \mathrm{C}$ temperature, 2,6,10 min. reaction time and 200, 400, $600 \mathrm{rpm}$, the surface angle of the coatings on the glass surface varies between 126-138, $5^{\circ}$. Three-factor Box-Behnken design method was used. When the obtained graphs and the response surface equation between the obtained response surface and the independent variable are examined, It was determined that the most important parameter was the mixing speed, the second important parameter was the temperature, and the reaction time parameter had very little effect on the ignition. It was determined that it would be appropriate to select primarily $\mathrm{pH}$, solid liquid concentration in factor instead of reaction time.
\end{abstract}

Keywords: Copper Stearate, Box-Behnken Design, Hydrophobic.

\footnotetext{
${ }^{1}$ Sorumlu Yazar: Yıldız Teknik Üniversitesi, Kimya Metalurji Fakültesi, Kimya Müh. Bölümü, İstanbul, Türkiye, ORCID: 0000-0001-8846-0674, keyf@yildiz.edu.tr
} 


\section{Giriş}

Süper hidrofobikliğin bilim dünyasıyla tanışması nilüfer bitkisinin yapraklarının bu özelliğe sahip olmasının keşfiyle başladı. nilüfer, drosera, okaliptüs, gingko biloba, sütleğen gibi bitkilerin ve irisin süper hidrofobik yapıya sahip olduklarını belirtmişlerdir. Bu yüzeylerin ortak özellikleri; yüzeyleri hidrofobik yapan çoğunlukla yüzeyindeki $-\mathrm{CH}_{2}-$ gruplarından oluşan parafinik balmumu kristalleriyle kaplı olmalarıdır (Barthlott ve Neinhuis, 1997).

Basit bir ifadeyle sslatmama özelliğine sahip süper hidrofobik eldesi için birincisi yüzey enerjisi düşük olan bir malzemenin yüzeyini pürüzlü hale getirmek, ikincisi ise pürüzlü olan bir yüzeyi yüzey enerjisi düşük olan bir malzeme ile modifiye etmektir (Minglin ve Randal, 2006).

Doğal süperhidrofobik lotus çiçeği, lotus yapraklarının SEM fotoğrafları incelendiğinde nano ve mikro yapıların yüzeye pürüzlülük kazandırdığg gözlemlenmiştir. Pürüzsüz bir yüzeye sahip olmak yerine, mikroskobik veya moleküler ölçekte bir yüzey desenine sahip olmak büyük farklar yaratıyor. Su damlaları lotus yaprağı üzerinde 150 derece civarında bir temas açısına sahiptir. Superhidrofobik özellik göstermektedir. Lotus bitkisi kendini \%99 temiz tutmayı başarıyor (Bharat, 2016). Süper hidrofobik bir yüzeyin üretimi uygun pürüzlülükte düşük enerjili bir yüzey oluşumu gereklidir. Pürüzlülük, eğim kriterlerine tamamen yerine getirmeli ve düşük enerjili yüzey Young temas açısı ile bağlantılı olmalıdır. Nakajima ve arkadaşları tarafindan superhidrofobikr yüzey oluşturmak için dolgu maddelerinin ilavesi (silika taneleri, PTFE taneleri, cam taneleri), püskürtme metoduyla, plazma polimerizasyonuyla, florit taneleriyle kaplayarak, CVD tekniği ile, ilave malzemelerin süblimasyonuyla, faz ayrışımı ve kalıplama şeklinde metodlar mevcuttur (Nakajima ve ark., 2001).

Ma ve arkadaşları tarafından süperhidrofobik yüzeylerin elde edilmesinde düşük yüzey enerjili maddelerle yüzeyin pürüzlü hale getirilmesi ve pürüzlü yüzeyin düşük yüzey enerjili madde ile modifiye edilmesi şeklinde basitçe iki ana grupta incelenmiştir. Yapılan çalışmada yüzey morfolojisi ve ıslanma özelliği arasındaki ilişki teorik olarak açıklanmıştır (Ma ve Hill , 2006). Yüzeylere hidrofobik ve oleofobik özellik kazandırmak amacıyla kullanılan floro karbonlu yapılar genellikle 2 kategoride toplanmaktadır. Bunlar; ana zincir yapısında sadece C-F bağına sahip olan floro polimerler ve yapısında flor ve klor veya hidrojen gibi diğer atomlar bulunduran floro kimyasallar olup daha az C-F bağı içerirler. Florun yapıya sağladığı atmosfer direnci, düşük sürtünme katsayısı, yüzeyde kir-su tutmama, gibi karakteristik özelliklerden dolayı kaplamalarda oldukça caziptir (Jiri, 2001).

Gu ve arkadaşlarının yaptığı çalışmada su temas açısı 146 dereceden büyük saydam süperhidrofobik film üretmek için kendi kendine toplanmış silika nano-tanecikler ve heptadekaflorodesiltrimethoksilan (HFTS) bazlı basit bir yöntem kullanılmışlardır (Gu ve ark., 2006). Daoud ve arkadaşlarının yaptığı çalışmada hidrofobik modifiye edilmiş silika nanokompozitler düşük sıcaklık sol-gel prosesi kullanılarak hazırlanmıştır. Bu çalışmada alkyltriethoxysilane; çapraz bağlayıcı (3-glycidoxypropyltrimethoxysilane (GPTMS)), hexdecyltrimethoxysilanenın (HDTMS) ve tetraethoxyorthosilicate (TEOS) ile kondensazyon reaksiyonu ile türetilmiştir Temas açısı ölçümleri kullanılarak hidrofobiközellikler belirlenmiştir. Yarı küresel nano-yapılı kompozit 50-75 nm çapında malzeme elde edildiğini göstermiştir. Nanokompozitlerin kimyasal yapıları FTIR analizleri incelendiğinde çapraz bağlayıcının eklenmesinin kompozit malzemenin kararlılığını arttırdığı gözlemlenmiştir (Daoud, 2006). Erbil ve arkadaşlarının süperhidrofobik yüzeylerin genellikle yüzey kimyasının ve yüzey pürüzlülüğünün arttırılması ile elde edildiği belirtilmiştir. Yaptıkları çalışmada yüzey pürüzlülügünün arttırılması için uygun sıcaklık ve uygun bir çözücü seçimiyle polipropilen kullanılarak ucuz bir metotla süperhidrofobik kaplama elde etmişlerdir (Erbil, 2003).

Jung ve arkadaşları tarafından süperhidrofobik yüzeylerde, katı-hava-sıvı kompozit ara yüzeyinden, homojen katı-sıvı ara yüzeye geçiş sırasında, su damlacıklarının boyutu ve yüzeyin geometrik parametreleri arasındaki ilişki incelenmiştir (Jung ve Bhushan, 2007). Nano ölçekte yaklaşık 20-100 mikrometre yüksekliğine sahip kimyasal madde sentezlenmesiyle yüzeylerde kaplama yapılarak aynı anda hidrofobik ve antibakteriyel etkiye sahip yüzeyler elde edilebilir. Hidrofobik ve antibakteriyel özelliğe sahip yüzeyler sağlık, gida ve tekstil gibi sektörlerde kullanımı giderek artmaktadır. Bakırstearat, bakır molekülüyle dolayı antibakteriyel etkiye sahiptir. Stearat moleküyle hidrofobik özellik kazandırılmasıyla hibrit özellikte mikron boyutta bakır stearat sentezlenmesi için Box-Behnken tasarım kullanılarak değişkenler ile cevap yüzeyi elde edilmiştir.

\subsection{Deneysel Tasarım}

Deneysel tasarım, prosesi etkileyen değişkenlerin (faktörlerin) belirlenmesi, açıklanması ve proses modelinin geliştirilmesidir (Cochran ve Cox, 1957). Deneysel tasarımda, deneyi etkileyen bağımsız değişkenlere faktör denir. Her bir faktörü oluşturan eşit aralıkta alınan faktör değerlerinin sayısına "seviye", deneylerden elde edilen sonuçların ölçümlerine ise "cevap" denir ( Lundstedt ve ark., 1998; Kuehl, 2000). Deneysel tasarımın deney için uygun değişkenleri belirleme ve değişkenlerin optimum olduğu değerler belirlenir. Optimizasyon ise, literatür özetledikten sonra deneysel çalışmadaki değişkenlerinin en etkili sonucu verdiği noktadaki değerleri elde etmektir. Genellenmiş model varyans analizi (ANOVA) ile değerlendirilir ( Açıkalın, 2010).

\subsubsection{Box-Behnken tasarım yöntemi}

Tasarımların temellerinde oluşturulan modellerin geliştirilmesi ve optimum deney şartlarının belirlenmesi için kullanılan BoxBehnken yöntemi üç seviyeli olup faktör ve cevap yüzeyi, sayısı artırılabilir ikinci dereceden çok değişkenli bir polinom veren tasarımdır. Cevap yüzeyi sonuçları değişkenlerin maksimum ya da minimum değerleri aralığında belirlenmesini sağlar. Faktöriyel tasarımlarına ilave olarak çalışma alanının köşe noktalarını birleştiren orta noktalar ve merkezde yapılan tekrar deneyleri kullanılır. Box-Behnken yöntemin yararları, daha az deney sayısı i ve merkezi bileşik tasarımına alternatif olarak gösterilmesidir (Khajeh, 2009a; Tripathi ve ark., 2009). Üç faktörlü Box-Behnken tasarımı için temsili gösterim Şekil 1'de gösterilmiştir (Açıkalın, 2010).

Box-Behnken Tasarımı üç seviyeli bir tasarımdır ve kodlama -1, 0 ve +1 olarak gösterilir. Tasarımdaki deney sayısı (N), $\mathrm{k}$ faktör sayısı ve $\mathrm{n} 0$ merkezde tekrarlanan deney sayısı olmak üzere, $\mathrm{N}=2 \mathrm{k}(\mathrm{k}-1)+\mathrm{n} 0$ denklemiyle hesaplanır. 




Şekil 1. Üç faktörlü Box-Behnken tasarımı için temsili gösterimi.

Bu çalışmada Box-Behnken Tasarım yöntemi ile model eldesi için (1) eşitliği ikinci dereden polinom (Quadratic) model olarak kullanılmıştır (Korkut, 2011).

$Y: \beta_{0}+\beta_{A} A+\beta_{B} B+\beta_{C} C+\beta_{A B} A B+\beta_{A C} A C+\beta_{B C} B C+\beta_{A A} A^{2}+\beta_{B B} B^{2}+\beta_{C C} C^{2}$

\section{Materyal ve Metot}

\subsection{Kullanılan Kimyasallar \\ $\mathrm{Cu}\left(\mathrm{C}_{2} \mathrm{H}_{3} \mathrm{O}_{2}\right)_{2} \mathrm{H}_{2} \mathrm{O}$ \\ Bakır Asetat \\ $\mathrm{C}_{2} \mathrm{H}_{5} \mathrm{OH}$ \\ Etil Alkol \\ $\mathrm{CH}_{3}\left(\mathrm{CH}_{2}\right)_{16} \mathrm{COOH}$ \\ Stearik Asit}

\subsection{Kullanılan Cihazlar}

Manyetik Karıştırıcılı Isıtma Cihazı

Hassas Terazi

Kamrera Düzeneği

\subsection{Bakır Asetat ve Stearik Asit Çözeltilerinin Hazırlanması}

0.75 gram bakır asetat hassas terazide tartıldı ve $100 \mathrm{ml}$ etil alkol ile çözülmüştür. Bakır asetat ve stearik asit arasındaki stokiyometrik oran dikkate alınarak (Eşitlik 1 ) 2.37 gram stearik asit hassas terazide tartıldı ve tartılan stearik asit $100 \mathrm{ml}$ etil alkol ile çözülmüş̧ür. Daha sonra stearik asit çözeltisi yavaşça bakır asetat çözeltisine ilave edildi ve her bir çözelti için Tablo 1'de görülen sıcaklık, zaman ve karıştırma hızları uygulanarak Manyetik karıştırıcılı 1sıtma cihazında $200 \pm 50 \mu \mathrm{m}$ boyutta bakır stearat elde edilmiştir. Reaksiyon denklemi;

$\mathrm{Cu}\left(\mathrm{C}_{2} \mathrm{H}_{3} \mathrm{O}_{2}\right)_{2}+\left[\mathrm{CH}_{3}\left(\mathrm{CH}_{2}\right)_{16} \mathrm{COOH}\right] \longrightarrow \mathrm{C}_{36} \mathrm{H}_{42} \mathrm{CuO}_{4}$

\section{Araştırma Sonuçları ve Tartışma}

\subsection{Bakır Stearat Çözeltilerinin Temas Açısı}

Hazırlanan bakır stearat çözeltileri daldırma metoduyla cam yüzeylere kaplandı. Yüzeylerin hidrofobik etkilerini daha iyi gözlemleyebilmek amacıyla kaplamadan önce cam yüzeye su damlatılarak temas açısı ölçüldü. Cam yüzey ile suyun yaptığı temas açısı $35^{\circ} \pm 2$ bulundu. Hazırlanan 17 adet farklı bakır stearat çözeltisiyle kaplanan cam yüzeylerin her birinin suyla yaptığ temas açıları ölçüldü ve temas açıları ölçülerek tablo 2'de belirtilmiştir.

Deneysel verilere göre hazırlanan bakır stearatlarla kaplı cam yüzeylerde suyun temas yüzeyiyle yaptığı temas açıları dikkate alındığında, sırasıyla en yüksek temas açısı ( hidrofobiklik) 5. orta hidrofobiklik 13. ve endüşük temas açısı 8. çözeltide tespit edilmiştir. 


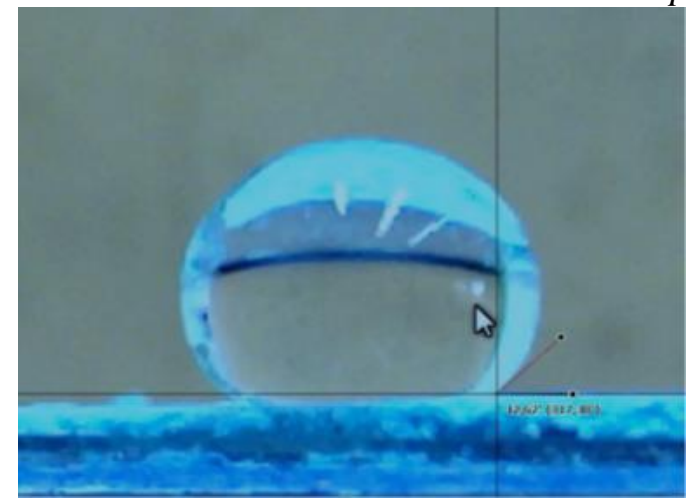

Şekil 5. Yüksek temas temas açılı 5.numune.

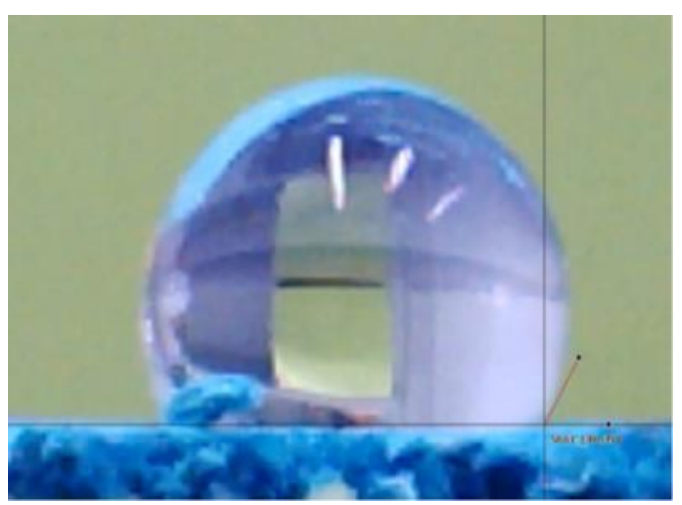

Şekil 6. En düşük temas açılı 8.numune.

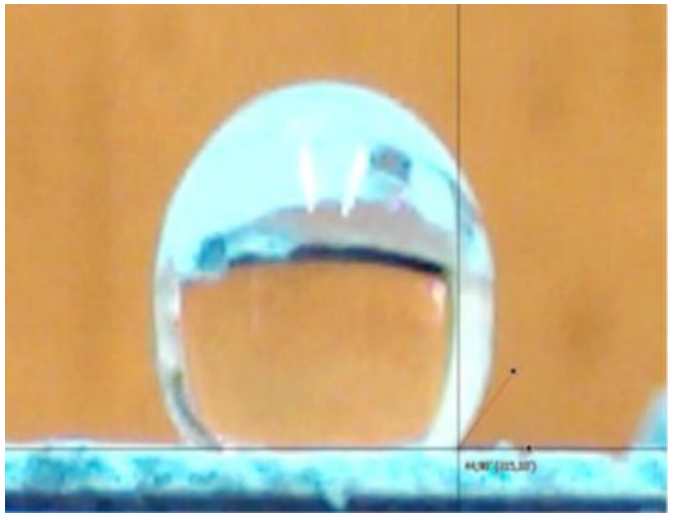

Şekil 7. Orta temas açılı 13.numune.

\subsection{Deneysel Tasarım Uygulaması}

Deneysel tasarım uygulamasında Design Expert 7.0.0 programı kullanıldı. Cevap yüzeyi bakır stearatın suyla yaptığı temas açısı R' yi etkileyen parametreler A: sıcaklık $\left({ }^{\circ} \mathrm{C}\right)$, B: reaksiyon zamanı (dak. ), C: karıştırma hızı (rpm) olarak belirlenmiştir.

Tablo 1. Box-Behnken tasarımı parametre (faktör) kodları.

\begin{tabular}{|l|l|l|l|}
\hline $\begin{array}{l}\text { Faktör } \\
\text { kodu }\end{array}$ & $\begin{array}{l}(\mathbf{A}) \\
\text { Sıcaklık } \\
\left({ }^{\mathbf{}} \mathbf{C}\right)\end{array}$ & $\begin{array}{l}\text { (B) Reak. } \\
\text { zamanı } \\
(\text { dak.) }\end{array}$ & $\begin{array}{l}\text { Karıştırma } \\
\text { hızı } \\
(\mathbf{r p m})(\mathbf{C})\end{array}$ \\
\hline 1 & 60 & 10 & 600 \\
\hline 0 & 40 & 6 & 400 \\
\hline-1 & 20 & 2 & 200 \\
\hline
\end{tabular}

Behnken tasarımı değişkenleri ve cevap yüzeyi Tablo 2'de belirtilmiştir.

Anova çözümleri sonucu 0.95 doğrulukta bakır stearat mikro tanecik eldesinde sıcaklık (A), reaksiyon zamanı(B) ve karıştırma hızı (C) değişkenleri ile temas açısı (R1) cevap yüzeyiyle bağlantılı faktör kodlarına bağlı olarak elde edilen matematiksel denklem; deneysel veriler kullanılarak, cevap yüzeyi fonksiyonunun katsayılarını veren regresyon analizi ve F-anlamlılık testine uyan terimler dikkate alındığında, Temas açısı için geliştirilen model denklemi eşitlik 2 de verilmiştir. 
$\mathrm{R} 1($ Temas açısı $)=132,74+2,75 \mathrm{~A}+1,19 \mathrm{~B}+3,56 \mathrm{C}-0.62 \mathrm{AB}-0,63 \mathrm{AC}-1 \mathrm{BC}$

Model 114.172 F değeri, modelin önemli olduğunu göstermektedir. Temas açısı model denklemi için (R1), kalanların toplamı 2.62, korelasyon katsayısı ise 0,9991olarak bulunmuştur. Varyans analizinin sonuçları Tablo 3 'te gösterilmektedir.

Tablo 2. Box-Behnken tasarımında Tasarımına uygun yapılan deneylerin sonuçları.

\begin{tabular}{|c|c|c|c|c|}
\hline $\begin{array}{l}\text { Deney } \\
\text { Sayısı }\end{array}$ & $\begin{array}{l}\text { Sıcaklık } \\
\left({ }^{\mathbf{}} \mathbf{C}\right) \mathbf{1}\end{array}$ & $\begin{array}{l}\text { Zaman } \\
(\mathbf{d a k} .)\end{array}$ & $\begin{array}{l}\text { Karış. } \\
\text { hızı } \\
(\mathbf{r p m})\end{array}$ & $\begin{array}{l}\text { Temas } \\
\text { açısı ( } \\
\pm \mathbf{2}\end{array}$ \\
\hline $\mathbf{1}$ & 60 & 10 & 400 & 136 \\
\hline $\mathbf{2}$ & 60 & 2 & 400 & 135 \\
\hline $\mathbf{3}$ & 20 & 10 & 400 & 131.5 \\
\hline $\mathbf{4}$ & 20 & 2 & 400 & 130 \\
\hline $\mathbf{5}$ & 60 & 6 & 600 & 138.5 \\
\hline $\mathbf{6}$ & 60 & 6 & 200 & 132 \\
\hline $\mathbf{7}$ & 20 & 6 & 600 & 134.5 \\
\hline $\mathbf{8}$ & 20 & 6 & 200 & 126 \\
\hline $\mathbf{9}$ & 40 & 10 & 600 & 137 \\
\hline $\mathbf{1 0}$ & 40 & 10 & 200 & 131 \\
\hline $\mathbf{1 1}$ & 40 & 2 & 600 & 135.5 \\
\hline $\mathbf{1 2}$ & 40 & 2 & 200 & 126.5 \\
\hline $\mathbf{1 3}$ & 40 & 6 & 400 & 133 \\
\hline $\mathbf{1 4}$ & 40 & 6 & 400 & 133.5 \\
\hline $\mathbf{1 5}$ & 40 & 6 & 400 & 133 \\
\hline $\mathbf{1 6}$ & 40 & 6 & 400 & 132.5 \\
\hline $\mathbf{1 7}$ & 40 & 6 & 400 & 133.5 \\
\hline
\end{tabular}

Tablo 3. Box-Behnken Tasarımıyla elde edilen temas açısı denklemi için ANOVA analizi sonuçları.

\begin{tabular}{|c|c|c|c|c|c|}
\hline \multirow{2}{*}{ MADDE } & KAYNAK & $\begin{array}{c}\text { SERBESTLIK } \\
\text { DERECESİ (v) }\end{array}$ & $\begin{array}{c}\text { KARELERIN } \\
\text { TOPLAMI (SS) }\end{array}$ & $\begin{array}{c}\text { ORTALAMA } \\
\text { KARE (MS) }\end{array}$ & $\begin{array}{c}\text { F } \\
\text { ORANI }\end{array}$ \\
\hline \multirow{3}{*}{ SK } & MODEL & 6 & 180.44 & 30.07 & 114.17 \\
\cline { 2 - 4 } & KALAN & 10 & 2.62 & 0.262 & \\
\cline { 2 - 6 } & TOPLAM & 16 & 183,08 & & \\
\hline
\end{tabular}

0.9563'teki "Tahmin R-kare", 0.9771'in "Düzeltilmiş R-kare" ile makul bir uyum içindedir. "Adeq Precision", sinyal / gürültü oranını ölçer. 4'ten büyük bir oran arzu edilir. 38.428 oranı yeterli bir sinyali belirtir. Bu model, tasarım alanında kullanılabilir. Varyans analizi sonucunda Design Expert yazılımıyla temas açısı modeli için hesaplanan P değeri (P value) 0,0001'den küçük bulunmuştur. P değerleri 0,01 den küçük olduğundan elde edilen model denklemi \%99 önem seviyesi şartını sağlamaktadır. Ayrıca Design Expert 7.0.0 programı kullanılarak sıcaklık, zaman ve karıştırma hızı parametrelerinin üç boyutlu grafikleri elde edildi ( Şekil 8, Şekil 9 ve Şekil 10).

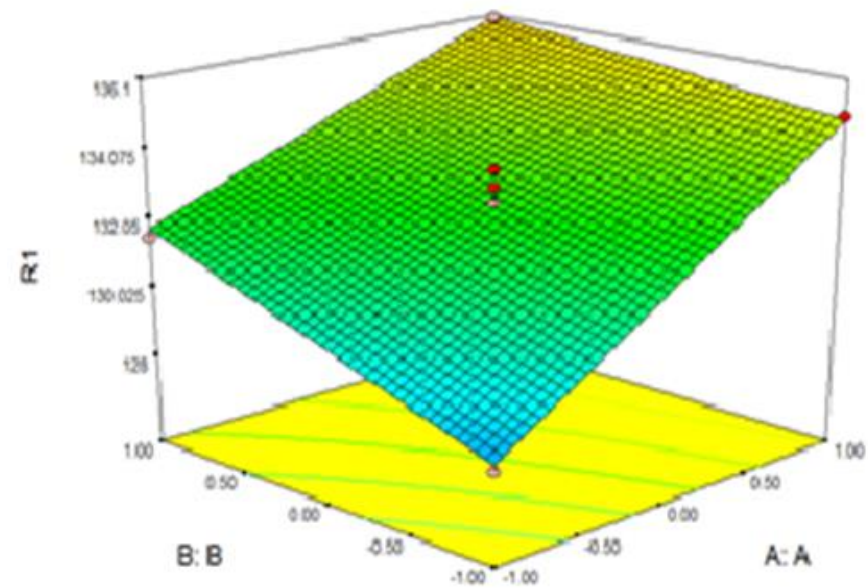

Şekil 8. Reaksiyon zamanı (dak.) - Sıcaklık $\left({ }^{\circ} \mathrm{C}\right)$ değişiminin temas açısına etkisi. 


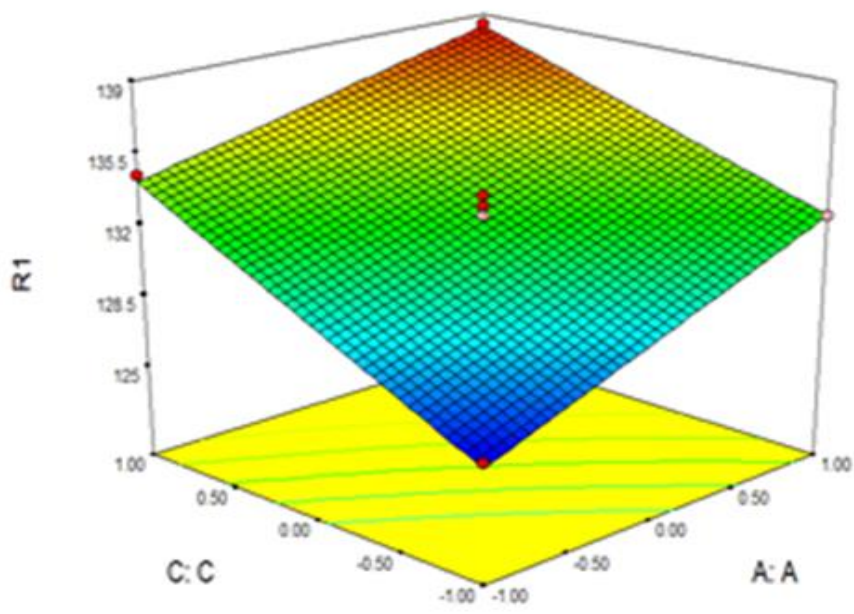

Şekil 9. Karıştırma hızı (rpm) - Sıcaklık $\left({ }^{\circ} \mathrm{C}\right)$ değişiminin temas açısına etkisi.

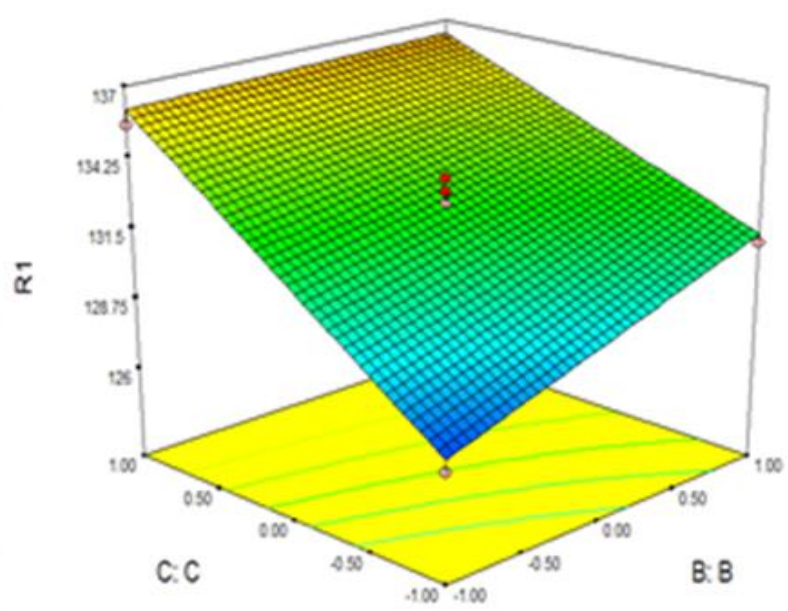

Şekil 10. Karıştırma hızı (rpm)-Zaman (dak.) değişiminin temas açısına etkisi.

\subsubsection{Bakır stearat sentezinde Box-Behnken tasarım optimizasyonu}

Reaksiyon sıcaklığı, reaksiyon zamanı ve karıştırma hızı temas açısını en yüksek yapacak ve mühendislik olarak reaksiyon süresi ve zamanı az olması yanısıra karıştırma hızınında az olması hedeflenerek temas açısının (hidrofobiklik ) max olması için yapılan optimizasyon seçeneklerinde arzu edilebilirlik 1 olan seçeneklerden ; A reaksiyon sicaklığ $1\left({ }^{\circ} \mathrm{C}\right) 0.97$ ( sicaklık yaklaşık 56- $58{ }^{\circ} \mathrm{C}$ arası ) , B reaksiyon zamanı ( dak.) - 0.94 ( 5.8-5.9 dak. arası ) ve C karıştırma hızı (rpm) 0.99 ( karıştırma hızı $595-599$ rpm) kodlu değerleri sağlayan temas açısı 138.691 seçilmiştir.

\section{Sonuç}

Yüzey üzerinde oluşturulan mikron büyüklükteki hidrofobik bakır stearatın yüzey pürüzlülüğü ve pürüzlülük içindeki hava arttıkça su damlasının yüzeyle yaptığı temas açısı artmaktadır. Cam yüzeyi üzerinde suyun temas açısının açısı $35^{\circ} \pm 2$ derece olduğu tespit edilmiştir. Cam yüzey üzerine bakır stearat çözeltisiyle yapılan kaplamayla su damlatıldığında temas açıları ölçülmüştür. $20,40,60{ }^{\circ} \mathrm{C}$ sıcaklık, 2, 6, 10 dak. reaksiyon zamanı ve 200, 400, 600 rpm karıştırma hızı değişkenlerine göre yapılan deneylerde bakır stearatın

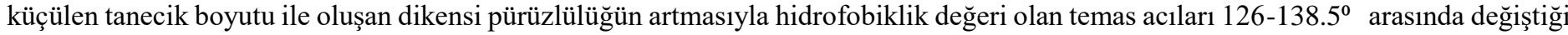
tespit edilmiştir. Design Expert 7.0.0 programı kullanılarak üç faktörlü Box-Behnken tasarım yöntemi kullanılmıştır. Elde edilen cevap yüzeyi ile bağımsız değişkenler arasında elde edilen grafikler ve cevap yüzeyi denklemi incelendiğinde; en etkili bağımsız değişkenin karıştırma hızı olduğu, ikinci önemli sıcaklık parametrenin olduğu, reaksiyon zamanı parametresinin ise temas açısındaki etkisinin çok az olduğu belirlenmiştir. Mikro ölçekte bakır stearat sentezinde sıcaklık 20-60 ${ }^{\circ} \mathrm{C}$ arasında sıcaklık arttıkça temas açısı artmaktadır. 600 rpm karıştırma hızından yüksek hızlarda denemeler yapılması uygundur. Reaksiyon zamanı 2 - 10 dak. aralığı temas açısına etkisi azdır. Reaksiyon zamanı 0 - 2 dakika aralığında deney değişkeni olarak incelenmesi önerilmektedir. $200 \pm 50 \mu \mathrm{m}$ boyutta bakır stearat sentezinde, cevap yüzeyi olarak parçacık boyut analizi değişimi incelenmesi mümkündür.

Box-Behnken tasarım optimizasyonu yapılarak; A reaksiyon sıcaklığ $\left({ }^{\circ} \mathrm{C}\right) 0.97$ ( sıcaklık yaklaşık $38-39{ }^{\circ} \mathrm{C}$ arası ), B reaksiyon zamanı ( dak.) - 0.94 ( 2.2.-2.4 dak. arası ) ve C karıştırma hızı (rpm) 0.99 ( karıştırma hızı 590-599 rpm ) kodlu değerleri sağlayan temas açısı 138.691secilmiştir. Bakır stearat parçacık boyutunun küçültülmesi dolayısıyla hidrofobikliğin arttırılması amacıyla 


\section{Avrupa Bilim ve Teknoloji Dergisi}

bağımsız değişken olarak reaksiyon zamanı yerine $\mathrm{pH}$ veya Bakır asetat (gr.) ve stearik asit (gr.) miktarı ile çözücü etil alkol miktarının (ml) oranı değiştirilerek seyreltik çalışılmasıyla partikül boyutunun azaltılarak deneysel tasarım çalışması yapılmasını önerilmiştir.

\section{Kaynakça}

Barthlott, W. \& Neinhuis, C. (1997). Purity of the sacred lotus, or escape from contamination in biological Surfaces. Planta , 202 (2): $1-8$.

Minglin, M. \& Randal, M.H. (2006). Superhydrophobic surfaces. Current Opinion in Colloid \& Interface Science, 11: 193-202.

Bharat, B. (2016). Biometics : bioinspried hierarchical - structured surfaces for green science. Second Edition Springer, 384-390.

Nakajima, A., Saiki. C., Hashimoto, K., \& Watanabe ,T. (2001). Processing of roughened silica film by coagulated colloidal silica for super-hydrophobic coating. Journal of Materials Science Letters, 20 (21) : 1975-1977.

Ma, M., \& Hill, R. M. (2006). Superhydrophobic surfaces. Colloid Interface Science, 11 (4): 193-202.

Jiri, G. D. (2001). Blends and composites based on fluoropolymers. Macromolecular Symposia, 170: 149-156.

Gu, G., Dang. H., Zhang Z., \& Wu, Z. (2006). Fabrication and characterization of transparent superhydrophobic thin films based on silica nanoparticles. Appl. Phys. A., 83 (1): 131-132.

Daoud, W. A., Xin, J. H., \& Tao, X, (2006). Synthesis and characterization of hydrophobic silica nanocomposites. Applied Surface Science, 252 (15): 5368-5371.

Erbil, H. Y., Demirel, A. L., Avci, Y., \& Mert, O. (2003). Transformation of a simple plastic into a superhydrophobic surface. Science, 299 (5611): 1377-1380.

Jung, Y. C., \& Bhushan B. (2007).Wetting transition of water droplets on superhydrophobic patterned Surfaces. Scripta Materialia, 57: 1057-1060.

Cochran W. G, \& Cox, G. M. (1992) . Experimental Design. 2nd. Edition, John Wiley \& Sons, New York.

Lundstedt, T., Seifert, E., Abramo, L., Thelin, B., Nyström, Ả., Pettersen, J., ve ark. (1998). Experimental Design and Optimization. Chemometrics and Intelligent Laboratory Systems, 42:3- 40.

Kuehl, R. O. (2000). Design of Experiments: Statistical Principles of Research Design and Analysis. 2nd. Edition, Duxbury, New York.

Korkut, A. (2010). Çeşitli Biyokütle Atık Maddelerin Pirolizi ve Elde Edilen Ürünlerin Analizi. FBE Kimya Mühendisliği Anabilim Dalı Doktora Tezi. 55-56.

Korkut, A., \& BOLAT, E. (2011). Siirt Fıstığı Kabuklarının Piroliz Ürün Verimlerinin Çeşitli Deneysel Tasarım Yöntemleri ile Modellenmesi. Journal of Engineering and Natural Sciences Mühendislik ve Fen Bilimleri Dergisi. 29: 52-64.

Khajeh, M. (2009a). Application of Box-Behnken Design in the Optimization of a Magnetic Nanoparticle Procedure for Zinc Determination in Analytical Samples by Inductively Coupled Plasma Optical Emission Spectrometry. Journal of Hazardous Materials, 172:385-389.

Tripathi, P., Srivastava, V. C., \& Kumari A. (2009). Optimization of an Azo Dye Batch Adsorption Parameters Using Box-Behnken Design. Desalination, 249:1273-1279. 